\title{
Impact of left ventricular dysfunction on early and late outcomes in patients undergoing concomitant aortic valve replacement and coronary artery bypass graft surgery
}

\author{
Akshat Saxena ${ }^{1}$, Ashvin Paramanathan ${ }^{1}$, William Y. Shi ${ }^{1}$, Diem T. Dinh ${ }^{2}$, \\ Christopher M. Reid ${ }^{2}$, Julian A. Smith ${ }^{3}$, Gilbert C. Shardey ${ }^{4}$, Andrew E. Newcomb ${ }^{1,5}$ \\ ${ }^{1}$ Department of Cardiothoracic Surgery, St. Vincent's Hospital Melbourne, Fitzroy, Victoria, Australia \\ ${ }^{2}$ Department of Epidemiology and Preventative Medicine, Monash University, Prahran, Victoria, Australia \\ ${ }^{3}$ Department of Surgery (MMC), Monash University and Department of Cardiothoracic Surgery, \\ Monash Medical Centre, Clayton, Victoria, Australia \\ ${ }^{4}$ Cabrini Medical Centre, Malvern, Victoria, Australia
}

${ }^{5}$ University of Melbourne Department of Surgery, St. Vincent's Hospital Melbourne, Fitzroy, Victoria, Australia

\section{Abstract}

Background: An increasing proportion of patients present for concomitant aortic valve replacement (AVR) and coronary artery bypass grafting (CABG) with left ventricular (LV) dysfunction. The aim of this study was to evaluate the early outcomes and late survival of patients with different degrees of LV function undergoing concomitant $A V R$ and $C A B G$.

Methods: Between June 2001 and December 2009, patients undergoing concomitant AVR-CABG were identified from the Australian and New Zealand Society of Cardiac and Thoracic Surgeons Cardiac Surgery Database Program. Demographic, operative data and post-operative outcomes were compared between patients with normal (> 60\%), moderately impaired (30$-60 \%)$, and severely impaired ( $<30 \%$ ) estimated LV ejection fraction (LVEF). Independent risk factors for short- and long-term mortality were identified using binary logistic and Cox regression, respectively.

Results: AVR-CABG was performed in 2,563 patients with a mean follow up of 36 months (range 0-106). 144 (5.6\%) had severely impaired LVEF, 983 (38.3\%) had moderately impaired LVEF while the remaining 1377 (53.7\%) had normal LVEF. The 30-day mortality in patients with severely impaired, moderately impaired and normal LVEF was 9.0\%, 4.3\% and 2.9\%, respectively. This was significant on univariate $(p<0.001)$ but not multivariate analysis $(p=N S)$. Severely impaired, moderately impaired and normal LVEF patients experienced 5 -year survivals of $63.7 \%, 77.1 \%$ and $82.5 \%$, respectively. Severely impaired LVEF was an independent multivariable predictor of late mortality (HR 1.71; 95\% CI 1.22-2.40; $p=0.002$ ).

Conclusions: Patients with severely impaired LVEF experience worse outcomes. However, in the era of modern surgery, this alone should not predicate exclusion, given the established benefits of surgery in this high-risk group. (Cardiol J 2013; 20, 4: 423-430)

Key words: cardiac surgery, coronary artery bypass graft, aortic valve replacement, ejection fraction, left ventricular dysfunction, morbidity, survival

Address for correspondence: Andrew E. Newcomb, Department of Cardiothoracic Surgery, University of Melbourne Department of Surgery, St. Vincent's Hospital Melbourne, Fitzroy, Victoria, Australia, tel: +61 39288 3989, fax: +61 39417 1694, e-mail: andrew.newcomb@svhm.org.au 


\section{Introduction}

Coronary artery disease, the leading cause of mortality and morbidity in the industrialised world, has traditionally been associated with poorer outcomes in patients undergoing aortic valve replacement (AVR) [1-4] for aortic stenosis. Improvements in surgical technique, myocardial preservation, perioperative management and earlier referral allows concomitant coronary artery bypass grafting (CABG) to be performed in selected patients undergoing AVR, resulting in satisfactory rates of operative mortality and a significant improvement in quality of life compared to medical therapy [1, 5-7].

Coronary artery disease and aortic valve disease are two of the most significant contributors to left ventricular (LV) dysfunction [8]. LV dysfunction is associated with poorer outcomes in most cardiac surgical procedures; patients with impaired or severely impaired ejection fraction $(\mathrm{EF})$ have inferior outcomes following isolated AVR or CABG procedures [2, 4, 8-12].

Previous work on AVR-CABG suggested LV dysfunction to be a predictor of poorer outcomes following regression analyses $[3,6,7,13,14]$. However, these studies did not directly correlate LV dysfunction with operative outcomes in AVR-CABG patients. Two studies assessed small cohorts of patients with LV dysfunction undergoing AVR-CABG and demonstrated inferior post-operative outcomes $[2,9]$. However, the multivariate analyses performed were specific to isolated AVR, not concomitant surgery. Long-term outcomes for concomitant AVR-CABG surgery were not documented in detail.

Given the paucity of data in this area and the growing recognition of minimally invasive approaches as viable alternatives, we aimed to establish the early and late outcomes in this high-risk population and identify pre-operative risk factors that may facilitate selection and peri-operative optimization $[15,16]$.

\section{Methods}

All patients undergoing isolated concomitant CABG and AVR between 1 June 2001, and 31 December 2009, at hospitals in Australia participating in the Australian and New Zealand Society of Cardiac and Thoracic Surgeons Cardiac Surgery Database were included in this study. Patients having isolated $\mathrm{CABG} /$ valvular surgery or other concurrent cardiac surgical procedures were excluded from this study. A detailed description of data collection and validation methods has been previously provided. The Ethics Committee of each participating hospital had previously approved the use of de-identified patient data contained within the database for research and waived the need for individual patient consent $[17,18]$.

In the current study, the preoperative characteristics, early outcomes, and long-term survival of patients with severely impaired $(<30 \%)$ and moderately impaired (30-60\%) LVEF were compared to those with a normal (>60\%) LVEF.

Fourteen early post-operative outcomes were analyzed. These were: a) 30-day mortality, defined as death within 30 days of operation; b) Permanent stroke, defined as a new central neurologic deficit persisting for $>72 \mathrm{~h}$; c) Transient stroke, defined as a new transient neurologic deficit that resolves completely within $72 \mathrm{~h}$ (transient ischemic attack or reversible ischemic neurologic deficit); d) Postoperative acute myocardial infarction, defined as at least 2 of the following: enzyme level elevation, new cardiac wall motion abnormalities, or new $\mathrm{Q}$ waves on serial electrocardiograms; e) New renal failure, defined as at least 2 of the following: serum creatinine increased to more than $200 \mu \mathrm{mol} / \mathrm{L}$, doubling or greater increase in creatinine vs. preoperative value, or new requirement for dialysis or hemofiltration; f) Prolonged ventilation (> $24 \mathrm{~h}$ ); g) Multi-system failure; defined as concurrent failure of 2 or more of the cardiac, respiratory or renal systems for at least $48 \mathrm{~h}$; h) Red blood cell transfusion; i) Gastrointestinal complications; defined as post-operative occurrence of any gastrointestinal complication; j) Deep sternal infection involving muscle and bone as demonstrated by surgical exploration and 1 of the following: positive cultures or treatment with antibiotics; k) Return to the operating theatre for any cause; and l) Return to the operating theatre for bleeding.

To assess the impact of LV dysfunction on 30-day mortality, logistic regression was used to adjust for 17 preoperative patient variables, with 30-day mortality as the dependent variable (variables in Table 3). Other early outcomes were compared on univariate analysis using the $\chi^{2}$ test. Long-term survival was obtained from the Australian National Death Index, the closing date for which was March 18, 2010. A Kaplan-Meier estimate of survival was obtained and differences in long-term survival were assessed by the log-rank test. The independent impact of $\mathrm{LV}$ dysfunction on long-term survival was assessed by constructing a Cox proportional hazards model using EF and other preoperative patient characteristics as variables. Continuous variables are presented as mean \pm 1 standard deviation and compared using the unpaired $t$ test and one-way analysis of variance 
Table 1. Comparison of pre-operative characteristics between the groups.

\begin{tabular}{|c|c|c|c|c|}
\hline Preoperative variables & $\begin{array}{l}\text { Normal LVEF } \\
(\mathrm{n}=1,377)\end{array}$ & $\begin{array}{l}\text { Impaired LVEF } \\
\quad(n=983)\end{array}$ & $\begin{array}{l}\text { Severely impaired } \\
\text { LVEF }(n=144)\end{array}$ & $\mathbf{P}$ \\
\hline Age [years] & $73.85 \pm 8.04$ & $74.47 \pm 8.43$ & $73.02 \pm 9.40$ & 0.061 \\
\hline Female & $497(36.1 \%)$ & $266(27.1 \%)$ & $29(20.1 \%)$ & $<0.001$ \\
\hline Chronic obstructive pulmonary disease & $221(16.0 \%)$ & $200(20.3 \%)$ & $34(23.6 \%)$ & 0.006 \\
\hline Diabetes mellitus & $406(29.5 \%)$ & $325(33.1 \%)$ & $50(34.7 \%)$ & 0.125 \\
\hline Hypercholesterolemia & $978(71.0 \%)$ & $707(71.9 \%)$ & $99(68.9 \%)$ & 0.701 \\
\hline Hypertension & $1108(80.5 \%)$ & $787(80.1 \%)$ & $106(73.6 \%)$ & 0.138 \\
\hline Cerebrovascular disease & $223(16.2 \%)$ & $196(19.9 \%)$ & $25(17.4 \%)$ & 0.065 \\
\hline Peripheral vascular disease & $166(12.1 \%)$ & $192(19.5 \%)$ & $34(23.6 \%)$ & $<0.001$ \\
\hline Renal failure & $39(2.8 \%)$ & $58(5.9 \%)$ & $7(4.9 \%)$ & 0.001 \\
\hline Previous cardiac surgery & $59(4.3 \%)$ & $77(7.8 \%)$ & $12(8.3 \%)$ & 0.001 \\
\hline Recent $\mathrm{MI}$ (< 21 days) & $91(6.6 \%)$ & $132(13.4 \%)$ & $36(25 \%)$ & $<0.001$ \\
\hline History of congestive heart failure & $380(27.6 \%)$ & $421(42.8 \%)$ & $111(77.1 \%)$ & $<0.001$ \\
\hline Triple vessel disease & $450(32.7 \%)$ & $421(42.8 \%)$ & $64(44.4 \%)$ & $<0.001$ \\
\hline Obesity & $452(32.8 \%)$ & $308(31.3 \%)$ & $34(31.3 \%)$ & 0.074 \\
\hline NYHA classification: & - & & - & $<0.001$ \\
\hline Class I & $273(19.8 \%)$ & $156(15.9 \%)$ & $4(2.8 \%)$ & - \\
\hline Class II & $537(39.0 \%)$ & $327(33.3 \%)$ & $30(20.8 \%)$ & - \\
\hline Class III & $475(34.5 \%)$ & $384(39.1 \%)$ & $68(47.2 \%)$ & - \\
\hline Class IV & $58(4.2 \%)$ & $100(10.2 \%)$ & $41(28.5 \%)$ & - \\
\hline Status: & - & - & - & $<0.001$ \\
\hline Elective & $1116(81.0 \%)$ & $678(69.0 \%)$ & $71(49.3 \%)$ & - \\
\hline Urgent/emergency/salvage & $261(19.0 \%)$ & $305(31.0 \%)$ & $73(50.7 \%)$ & - \\
\hline Critical preoperative state & $41(3.0 \%)$ & $67(6.8 \%)$ & $35(24.3 \%)$ & $<0.001$ \\
\hline
\end{tabular}

LVEF — left ventricular ejection fraction; MI - myocardial infarction; NYHA — New York Heart Association

for the 3 categories of $L V$ function. The $\chi^{2}$ test was used to compare groups of categoric variables. All calculated values of $\mathrm{p}$ were 2 -sided, and $\mathrm{p}<0.05$ was considered significant. Statistical analysis was performed using SPSS ${ }^{\oplus}$ for Windows version 17.0 (SPSS Inc., Chicago, Illinois).

\section{Results}

Concomitant AVR-CABG surgery was performed in 2,563 patients at 18 Australian institutions; of these, estimated EF was recorded in 2,504. One thousand three hundred and thirty seven (53.7\%) patients had a normal EF, $983(38.3 \%)$ had a moderately impaired EF and 144 (5.6\%) had a severely impaired EF. Pre-operative and demographic characteristics of patients, stratified by EF are provided in Table 1 . There were some notable differences in intra-operative variables between the three groups (Table 2).

Overall 30-day mortality and in-hospital mortality were $3.8 \%$ and $4.2 \%$, respectively. The unad- justed 30-day mortality rate was $2.9 \%$ in patients with normal EF, $4.3 \%$ in patients with impaired $\mathrm{EF}$ and $9.0 \%$ in patients with severely impaired EF. This difference was significant on univariate analysis $(\mathrm{p}=0.001)$. Logistic regression (Table 3 ) showed that impaired EF and severely impaired EF were not predictors of 30-day mortality on multivariate analysis. Patients with severely impaired and impaired EF had a significantly higher mean post-operative length of stay $(14.69 \pm 12.38$ vs. $12.32 \pm 11.07$ vs. $11.16 \pm 10.27, \mathrm{p}<0.001)$ and intensive care unit stay $(113.75 \pm 159.67$ vs. $68.64 \pm 104.30$ vs. $61.11 \pm 108.47 \mathrm{~h}, \mathrm{p}<0.001)$ compared to patients who had normal EF (Table 4).

The mean follow-up was 36 months (range $0-106)$. Long-term survival at 3 and 5 years was significantly lower on multivariate analysis in patients with severely impaired $\mathrm{EF}(\mathrm{p}=0.02)$, but not in those with impaired $\mathrm{EF}(\mathrm{p}=0.247)(88.4 \%$ vs. $84.1 \%$ vs. $69.2 \%, 82.5 \%$ vs. $77.1 \%$ vs. $63.7 \%$ ) compared to those with normal EF (Fig. 1). A Cox regression model predicting late mortality is shown in Table 5. 
Table 2. Comparison of intra-operative characteristics between the groups.

\begin{tabular}{lcccc}
\hline Preoperative variables & $\begin{array}{c}\text { Normal LVEF } \\
(\mathbf{n}=\mathbf{1 , 3 7 7 )}\end{array}$ & $\begin{array}{c}\text { Impaired LVEF } \\
\text { (n= 983) }\end{array}$ & $\begin{array}{c}\text { Severely impaired } \\
\text { LVEF (n= 144) }\end{array}$ & $\mathbf{P}$ \\
\hline Cardiopulmonary bypass time [min] & $112.93 \pm 36.22$ & $119.97 \pm 35.67$ & $117.63 \pm 33.79$ & $<0.001$ \\
Aortic cross-clamp time [min] & $142.00 \pm 44.53$ & $152.62 \pm 47.30$ & $155.70 \pm 47.94$ & $<0.001$ \\
Type of prosthesis & - & - & - & 0.816 \\
$\quad$ Bioprosthesis & $1121(81.4 \%)$ & $780(79.3 \%)$ & $118(81.9 \%)$ & - \\
$\quad$ Mechanical valve & $215(15.6 \%)$ & $154(15.7 \%)$ & $23(16.0 \%)$ & - \\
$\quad$ Other & $7(0.5 \%)$ & $9(0.9 \%)$ & $1(0.7 \%)$ & - \\
Number of distal anastomoses & $2.11 \pm 1.14$ & $2.34 \pm 1.11$ & $2.21 \pm 1.15$ & 0.031 \\
Internal mammary artery used & $979(71.1 \%)$ & $718(73.0 \%)$ & $90(62.5 \%)$ & $<0.001$ \\
Valve size & $22.77 \pm 2.18$ & $23.21 \pm 2.11$ & $23.38 \pm 2.13$ & $<$ \\
\hline
\end{tabular}

LVEF - left ventricular ejection fraction

Table 3. Comparison of early mortality outcomes between the groups.

\begin{tabular}{|c|c|c|c|c|}
\hline \multirow{2}{*}{$\begin{array}{l}\text { Preoperative variables } \\
\text { Early mortality }\end{array}$} & \multicolumn{2}{|l|}{ Univariate } & \multicolumn{2}{|c|}{ Multivariate } \\
\hline & Odds ratio $(95 \% \mathrm{CI})$ & $\mathbf{P}$ & Odds ratio $(95 \% \mathrm{Cl})$ & $\mathbf{P}$ \\
\hline Age & $1.06(1.03-1.09)$ & $<0.001$ & $1.05(1.04-1.06)$ & $<0.001$ \\
\hline Left ventricular ejection fraction & - & - & - & - \\
\hline Normal & 1.00 & - & 1.00 & - \\
\hline Impaired & $1.49(0.96-2.31)$ & 0.077 & $1.08(0.68-1.73)$ & 0.745 \\
\hline Severely impaired & $3.30(1.72-6.33)$ & $<0.001$ & $1.68(0.79-3.57)$ & 0.177 \\
\hline Female & $1.47(0.97-2.22)$ & 0.070 & $1.38(0.88-2.18)$ & 0.164 \\
\hline Chronic obstructive pulmonary disease & $1.18(0.72-1.96)$ & 0.511 & $1.03(0.61-1.74)$ & 0.905 \\
\hline Diabetes mellitus & $0.94(0.60-1.46)$ & 0.782 & $0.81(0.50-1.32)$ & 0.408 \\
\hline Hypercholesterolemia & $0.96(0.61-1.49)$ & 0.838 & $0.97(0.60-1.58)$ & 0.906 \\
\hline Hypertension & $1.09(0.65-1.84)$ & 0.737 & $1.01(0.57-1.77)$ & 0.986 \\
\hline Cerebrovascular disease & $2.04(1.30-3.19)$ & 0.002 & $1.69(1.05-2.72)$ & 0.032 \\
\hline Peripheral vascular disease & $2.18(1.38-3.45)$ & 0.001 & $1.51(0.91-2.50)$ & 0.108 \\
\hline Renal failure & $2.12(1.00-4.49)$ & 0.050 & $1.29(0.53-3.19)$ & 0.576 \\
\hline Critical preoperative state & $1.45(1.19-1.76)$ & $<0.001$ & $1.80(0.83-3.92)$ & 0.140 \\
\hline Triple vessel disease & $1.56(1.04-2.34)$ & 0.033 & $1.47(0.95-2.27)$ & 0.085 \\
\hline Reccent MI (< 21 days) & $1.23(0.92-1.64)$ & 0.166 & $0.72(0.37-1.43)$ & 0.348 \\
\hline Obesity & $0.70(0.44-1.11)$ & 0.128 & $0.98(0.59-1.62)$ & 0.926 \\
\hline History of congestive heart failure & $2.11(1.40-3.17)$ & $<0.001$ & $1.20(0.76-1.92)$ & 0.436 \\
\hline NYHA classification III or IV & $2.85(1.83-4.44)$ & $<0.001$ & $2.27(1.39-3.70)$ & 0.001 \\
\hline Non-elective procedure & $2.43(1.61-3.66)$ & $<0.001$ & $1.74(1.07-2.82)$ & 0.025 \\
\hline
\end{tabular}

MI - myocardial infarction; NYHA — New York Heart Association

\section{Discussion}

Chronic aortic valve stenosis leads to the development of compensatory mechanisms, which promote LV hypertrophy to maintain cardiac output $[12,13]$. Over time, these mechanisms fail and the resulting ventricular dilatation leads to increasing myocardial oxygen consumption and further decline in systolic function $[12,13,19]$. Most patients have underlying coronary vessel disease, which exacerbates myocardial ischemia and further erodes ventricular function $[12,13]$. With expanding geriatric populations in the developed world, aortic valve and coronary vessel pathology are prominent comorbidities that require concomitant surgery. Given the natural history of concomitant valve and vessel pathology, most patients undergoing combined AVR-CABG have a degree of underlying 
Table 4. Comparison of early outcomes between the groups.

\begin{tabular}{lcccc}
\hline Outcome & Normal LVEF & Imapired LVEF & Severely imapired LVEF & P \\
\hline Permanent stroke & $28(2.0 \%)$ & $19(1.9 \%)$ & $6(4.2 \%)$ & 0.213 \\
Transient stroke & $13(0.9 \%)$ & $9(0.9 \%)$ & $0(0 \%)$ & 0.506 \\
Post-operative MI & $13(0.9 \%)$ & $8(0.8 \%)$ & $3(2.1 \%)$ & 0.345 \\
New renal failure & $104(7.6 \%)$ & $98(10.0 \%)$ & $23(16.0 \%)$ & 0.001 \\
Deep sternal wound infection & $16(1.2 \%)$ & $11(1.1 \%)$ & $2(1.4 \%)$ & 0.961 \\
Septicemia & $26(1.9 \%)$ & $16(1.6 \%)$ & $4(2.8 \%)$ & 0.619 \\
Pneumonia & $75(5.4 \%)$ & $71(7.2 \%)$ & $15(10.4 \%)$ & 0.030 \\
Red blood cell transfusion & $814(59.1 \%)$ & $581(59.1 \%)$ & $99(68.9 \%)$ & 0.077 \\
Multi-system failure & $34(2.5 \%)$ & $17(1.7 \%)$ & $8(5.6 \%)$ & 0.018 \\
Prolonged ventilation & $175(12.7 \%)$ & $162(16.5 \%)$ & $46(31.9 \%)$ & $<0.001$ \\
Gastrointestinal complications & $37(2.7 \%)$ & $15(1.5 \%)$ & $6(4.2 \%)$ & 0.062 \\
Return to theatre & $127(9.2 \%)$ & $79(8.0 \%)$ & $18(12.5 \%)$ & 0.189 \\
Return to theatre for bleeding & $62(4.5 \%)$ & $35(3.6 \%)$ & $8(5.6 \%)$ & 0.373 \\
\hline
\end{tabular}

LVEF - left ventricular ejection fraction; $\mathrm{MI}$ - myocardial infarction

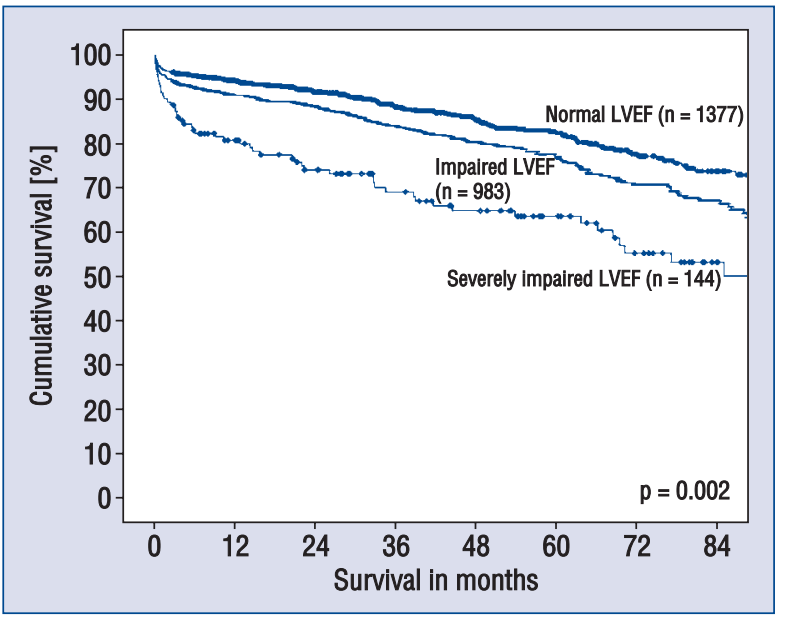

Figure 1. Survival outcomes, stratified by left ventricular ejection fraction (LVEF).

ventricular compromise - traditionally a harbinger of poorer surgical outcomes. The purpose of this study was to evaluate the impact of LV dysfunction on early and late outcomes following concomitant AVR-CABG in the context of multiple patient comorbidities, to determine if high-risk patients would benefit from an arduous, potentially risky procedure.

Patients with severe LV dysfunction were found to have worse early outcomes. Our results demonstrated an unadjusted 30-day mortality rate of $9.0 \%$ compared with $4.3 \%$ and $2.9 \%$ in patients with moderately impaired and normal ventricular function, respectively. This was significant on univariate but not on multi-variate analysis. The NYHA classification, traditionally only a subjective assessment of the degree of LV dysfunction, age and cerebrovascular disease was found to be an independent predictor of early mortality in our study [20]. Similarly, Chikwe et al. [2] demonstrated an $8 \%$ mortality rate in patients with $\mathrm{EF}<30 \%$ and severe aortic stenosis with low transvalvular gradients who underwent AVR-CABG, compared to a $2 \%$ mortality rate in patients with normal EF with no significant difference. In our study, the cohort with severely impaired LVEF experience with greater post-operative complications that included new renal failure, pneumonia, multi-system failure and prolonged ventilation; which is consistent with the study by Chikwe et al. [2]. It is well known that LV dysfunction may compound other co-morbidities, which may then further contribute to early mortality $[9,10,12]$. Modern myocardial protection strategies and improved perioperative care has stymied the adverse effects of prolonged ischemia during concomitant surgery with an in-hospital mortality of around $10 \%$ being achievable in experienced centers, compared with $20 \%$ a few decades ago [2]. Peri-operative management of LV dysfunction and other concurrent comorbidities is paramount in order to optimize surgical outcomes in this high-risk group.

Long-term outcomes were significantly worse in patients with severely impaired LV function and $\mathrm{LV}$ dysfunction was a predictor of inferior outcomes on multi-variate analysis. Our results are consistent with the existing literature. Kobayashi et al. [7] found survival in patients undergoing com- 
Table 5. Comparison of late mortality outcomes between the groups.

\begin{tabular}{|c|c|c|c|c|}
\hline \multirow{2}{*}{$\begin{array}{l}\text { Preoperative variables } \\
\text { Late mortality }\end{array}$} & \multicolumn{2}{|l|}{ Univariate } & \multicolumn{2}{|c|}{ Multivariate } \\
\hline & Odds ratio (95\% CI) & $\mathbf{P}$ & Odds ratio $(95 \% \mathrm{Cl})$ & $\mathbf{P}$ \\
\hline Age & $1.05(1.04-1.07)$ & $<0.001$ & $1.05(1.04-1.06)$ & $<0.001$ \\
\hline Left ventricular ejection fraction & - & - & - & - \\
\hline Normal & 1.00 & - & 1.00 & - \\
\hline Impaired & $1.39(1.13-1.70)$ & 0.002 & $1.14(0.92-1.41)$ & 0.247 \\
\hline Severely impaired & $2.58(1.91-3.49)$ & $<0.001$ & $1.71(1.22-2.40)$ & 0.002 \\
\hline Female & $1.10(0.90-1.34)$ & 0.361 & $1.14(0.92-1.41)$ & 0.243 \\
\hline Chronic obstructive pulmonary disease & $1.41(1.13-1.77)$ & 0.002 & $1.38(1.10-1.72)$ & 0.006 \\
\hline Diabetes mellitus & $1.12(0.92-1.37)$ & 0.276 & $1.11(0.89-1.37)$ & 0.364 \\
\hline Hypercholesterolemia & $0.86(0.70-1.05)$ & 0.146 & $0.84(0.68-1.04)$ & 0.117 \\
\hline Hypertension & $0.96(0.76-1.20)$ & 0.699 & $0.91(0.72-1.16)$ & 0.455 \\
\hline Cerebrovascular disease & $1.59(1.28-1.99)$ & $<0.001$ & $1.28(1.01-1.62)$ & 0.041 \\
\hline Peripheral vascular disease & $1.68(1.34-2.10)$ & $<0.001$ & $1.35(1.06-1.72)$ & 0.015 \\
\hline Renal failure & $2.63(1.87-3.71)$ & $<0.001$ & $1.76(1.17-2.64)$ & 0.007 \\
\hline Critical preoperative state & $2.81(2.13-3.71)$ & $<0.001$ & $1.65(1.15-2.36)$ & 0.006 \\
\hline Triple vessel disease & $1.46(1.21-1.76)$ & $<0.001$ & $1.29(1.06-1.58)$ & 0.012 \\
\hline Reccent $\mathrm{MI}(<21$ days $)$ & $1.89(1.45-2.46)$ & $<0.001$ & $1.25(0.91-1.72)$ & 0.165 \\
\hline Obesity & $0.74(0.59-0.92)$ & 0.006 & $0.89(0.71-1.13)$ & 0.348 \\
\hline History of congestive heart failure & $1.80(1.49-2.17)$ & $<0.001$ & $1.40(1.13-1.73)$ & 0.002 \\
\hline NYHA classification III or IV & $1.37(1.13-1.66)$ & 0.001 & $0.98(0.79-1.21)$ & 0.823 \\
\hline Non-elective procedure & $1.63(1.34-1.98)$ & $<0.001$ & $1.17(0.92-1.48)$ & 0.205 \\
\hline
\end{tabular}

MI - myocardial infarction; NYHA - New York Heart Association

bined AVR-CABG ranged from $63 \%$ to $72 \%$, while Chikwe et al. [2] demonstrated 5-year survival in patients with severe EF of $65 \%$. Similarly, Halkos et al. [9] demonstrated that the 5-year survival of AVR/CABG was $62 \%$ for EF less than $40 \%$. Given the high pre-operative risk and poorer long-term outcomes, previous studies have advocated for a more cautious approach towards patient selection in those with advanced LV failure. However, this must be considered in the context of the poor natural history of aortic stenosis with previous reports suggesting that patients have a life expectancy of only 2 years [12]. The increased operative risk must be balanced with the potential gain in both length and quality of life. Age is ultimately a significant factor that determines suitability for operative action, with several studies (including ours) demonstrating the detrimental effects of increasing age on short- and long-term outcomes following cardiac surgery [21, 22]. Patients with impaired LVEF presented with concurrent medical problems; several of these were demonstrated to predict long-term survival. Thus a rigorous pre-operative work-up and medical optimization should be performed, considering the person's age, ventricular function and other comorbidities in order to encompass the widest cohort of patients who will benefit from surgery. Future work looking at the effects of concomitant surgery in octogenarians with severely impaired $\mathrm{LV}$ dysfunction may be useful to identify if this cohort is a relative contraindication to surgery.

Indications for either a concomitant approach or an isolated approach for the dominant pathology are widely debated in the context of $\mathrm{LV}$ dysfunction. It is known that the combined approach portends an increased operative risk; our results reflect this trend $[15,23]$. Proponents of the combined approach argue that this population would avoid a second major procedure, and that subsequent regression in LV mass and improvement in $\mathrm{EF}$ confers upon them increased life expectancy and quality, and decreased re-intervention rates, which would not have been afforded had surgery not been performed [13, 19, 23, 24]. Opponents argue that the progression of the secondary pathology is slow and does not necessitate immediate action. Subsequent surgical intervention may be performed without additional risk. In valve replacement surgery for incidental aortic valve pathology, for instance, patients are unnecessarily exposed to additional risk factors associated with the operation, and subsequently require lifetime anti-coagulation 
$[13,19,23]$. Several studies, however, have shown that progression of asymptomatic aortic stenosis at the time of $\mathrm{CABG}$ to a state which requires an AVR averages between 4 and 9 years depending on the underlying pathology [13]. The additional risk of AVR-CABG in patients with LVEF is only slight, compared to patients with compromised LVEF undergoing single procedures; our results reflect this trend. Given the natural history of aortic valve and coronary vessel disease, with its deleterious effects on ventricular function, concomitant 'prophylactic' AVR-CABG in patients with normal to impaired LV dysfunction for varying severities of aortic stenosis at the time of CABG may be performed without additional risk [13]. This may avoid re-intervention after initial surgery to correct the secondary pathology, which may have progressed to cause impaired or severely impaired ventricular function; this subjects patients to a riskier operation, which could have been avoided if they had undergone a concomitant procedure [13, 19, 24].

For patients with severely impaired LVEF, we have shown comparable short-term outcomes and long term survival compared to studies analyzing single procedures in the context of severely impaired LVEF. For isolated AVR in patients with poor LV function, Halkos et al. [9] showed that patients with an $\mathrm{EF}$ between $25 \%$ and $40 \%$ had an in-hospital mortality of $14.5 \%$ and a 5 -year survival of $62 \%$. A systematic review by Kunadian et al. [8] demonstrated an operative mortality of $5.4 \%$ and a 5 -year survival of $73.4 \%$ in patients with a mean EF of $24.7 \%$ in patients undergoing isolated CABG. These results are similar to ours, which suggest that AVR-CABG may be performed safely in this population.

The poor prognosis of patients with LV dysfunction requiring concomitant surgery has led to several arguments being mooted in the literature supporting percutaneous intervention techniques. This mainly involves trans-apical or trans-femoral aortic valve implantation followed by percutaneous coronary intervention, both of which carry a significantly lower peri-operative risk and mortality in this subset of patients $[15,16]$. In patients seen to have a significant peri-operative risk with uncontrolled comorbidities, this may present itself as a viable option [25]. However, it should not be seen at this stage to be a panacea for patients with LV dysfunction requiring concomitant surgery. Studies continue to suggest that $\mathrm{CABG}$ achieves superior outcomes to percutaneous coronary intervention in patients with left main or triple vessel disease, especially those with diabetes [26, 27]. Moreover, conventional AVR is regarded as the gold standard in the management of severe symptomatic aortic stenosis although promising outcomes have been reported for transcatheter AVR more recently [28, 29]. Randomized studies, despite their logistic limitations are needed further investigate the efficacy of hybrid transcatheter valve and percutaneous revascularization procedures.

Out study is the largest multi-centre study of patients undergoing concomitant AVR-CABG. The data presented here was subjected to both local validation and external auditing. Hence, the level of accuracy of the reported pre-, intra- and post-operative variables, along with the operative complications and mortality rates, is high. However, it was subject to the usual caveats of retrospective work. Firstly, selection bias and confounding from unknown variables is likely to be present. Our dataset lacks information on drug medication preoperatively, at discharge and during follow-up. Patient characteristics were heterogeneous throughout, which may have introduced various bias and confounders to the results. Other long-term clinical endpoints which included re-occurrence of angina or need for further re-intervention were not available, which would have been useful to measure.

\section{Conclusions}

Our results demonstrate that combined CABG/ /AVR can be performed in this challenging subgroup of patients with results similar to isolated AVR replacement with severe LV dysfunction. Given the limitations of drawing concrete conclusions from retrospective work, patients should not be denied surgery based on their LV dysfunction alone. Rather, an individualized approach should be championed, with due consideration of all patient factors.

\section{Conflict of interest: none declared}

\section{References}

1. Jones JM, Lovell D, Cran GW, MacGowan SW. Impact of coronary artery bypass grafting on survival after aortic valve replacement. Interact CardioVasc Thorac Surg, 2006; 5: 327-330.

2. Chikwe J, Croft LB, Goldstone AB et al. Comparison of the results of aortic valve replacement with or without concomitant coronary artery bypass grafting in patients with left ventricular ejection fraction $<=30 \%$ versus patients with ejection fraction $>30 \%$. Am J Cardiol, 2009; 104: 1717-1721.

3. Jones M, Schofield PM, Brooks NH et al. Aortic valve replacement with combined myocardial revascularisation. Br Heart J, 1989; 62: 9-15.

4. Rankin JS, Hammill BG, Ferguson Jr TB et al. Determinants of operative mortality in valvular heart surgery. J Thoracic Cardiovasc Surgery, 2006; 131: 547-557. 
5. Lytle B, Cosgrove D, Loop F et al. Replacement of aortic valve combined with myocardial revascularization: determinants of early and late risk for 500 patients, 1967-1981. Circulation, 1983; 68: 1149-1162.

6. He G-W, Grunkemeier GL, Starr A. Aortic valve replacement in elderly patients: influence of concomitant coronary grafting on late survival. Ann Thorac Surg, 1996; 61: 1746-1751.

7. Kobayashi KJ, Williams JA, Nwakanma L, Gott VL, Baumgartner WA, Conte JV. Aortic valve replacement and concomitant coronary artery bypass: Assessing the impact of multiple grafts. Ann Thorac Surg, 2007; 83: 969-978.

8. Kunadian V, Zaman A, Qiu W. Revascularization among patients with severe left ventricular dysfunction: a meta-analysis of observational studies. Eur J Heart Failure, 2011; 13: 773-784.

9. Halkos ME, Chen EP, Sarin EL et al. Aortic valve replacement for aortic stenosis in patients with left ventricular dysfunction. Ann Thoracic Surgery, 2009; 88: 746-751.

10. Velazquez EJ, Lee KL, Deja MA et al. Coronary-Artery bypass surgery in patients with left ventricular dysfunction. N Engl J Med, 2011; 364: 1607-1616.

11. Connolly HM, Oh JK, Schaff HV et al. Severe aortic stenosis with low transvalvular gradient and severe left ventricular dysfunction: Result of aortic valve replacement in 52 patients. Circulation, 2000; 101: 1940-1946.

12. Chukwuemeka A, Rao V, Armstrong S, Ivanov J, David T. Aortic valve replacement: a safe and durable option in patients with impaired left ventricular systolic function. Eur J Cardio-Thoracic Surgery, 2006; 29: 133-138.

13. Du X, Soon JL. Mild to moderate aortic stenosis and coronary bypass surgery. J Cardiol, 2011; 57: 31-35.

14. Richardson J, Kouchoukos N, Wright J, Karp R. Combined aortic valve replacement and myocardial revascularization: results in 220 patients. Circulation, 1979; 59: 75-81.

15. Redlich K, Khaladj N, Peterss S et al. Conventional aortic valve replacement in patients with concomitant coronary artery disease and previous coronary artery bypass grafting in the era of interventional approaches. Eur J Cardio-Thoracic Surgery, 2011; 40:455-462.

16. Brinster DR, Byrne M, Rogers CD et al. Effectiveness of Same day percutaneous coronary intervention followed by minimally invasive aortic valve replacement for aortic stenosis and moderate coronary disease ('hybrid approach'). Am J Cardiol, 2006; 98: 1501-1503.

17. Dinh DT, Lee GA, Billah B, Smith JA, Shardey GC, Reid CM. Trends in coronary artery bypass graft surgery in Victoria, 20012006: findings from the Australasian Society of Cardiac and Thoracic Surgeons database project. Med J Aust, 2008; 188: 214-217.

18. Saxena A, Poh CL, Dinh DT, Smith JA, Shardey GC, Newcomb AE. Early and late outcomes after isolated aortic valve replacement in octogenarians: an Australasian Society of Cardiac and Thoracic Surgeons Cardiac Surgery Database Study. Eur J Cardiothorac Surg, 2011 [Epub ahead of print 2011/05/24].
19. Gillinov A, Garcia M. When is concomitant aortic valve replacement indicated in patients with mild to moderate stenosis undergoing coronary revascularization? Curr Cardiol Reports, 2005; 7: 101-104.

20. Hunt SA, Baker DW, Chin MH et al. ACC/AHA guidelines for the evaluation and management of chronic heart failure in the adult: executive summary: A report of the american college of cardiology/american heart association task force on practice guidelines (committee to revise the 1995 guidelines for the evaluation and management of heart failure) developed in collaboration with the international society for heart and lung transplantation endorsed by the heart failure society of america. J Am Coll Cardiol, 2001; 38: 2101-2113.

21. Saxena A, Dinh DT, Yap CH et al. Critical analysis of early and late outcomes after isolated coronary artery bypass surgery in elderly patients. Ann Thorac Surg, 2011; 92: 1703-1711.

22. Saxena A, Dinh D, Poh CL, Smith JA, Shardey G, Newcomb AE. Analysis of early and late outcomes after concomitant aortic valve replacement and coronary artery bypass graft surgery in octogenarians: a multi-institutional Australian study. J Am Geriatrics Society, 2011; 59: 1759-1761.

23. Alsoufi B KT, Slater M, Shen I, Ungerleider R, Ravichandran P. Results of concomitant aortic valve replacement and coronary artery bypass grafting in the VA population. J Heart Valve Dis, 2006; 15: 12-18.

24. Hochrein J, Lucke JC, Harrison JK et al. Mortality and need for reoperation in patients with mild-to-moderate asymptomatic aortic valve disease undergoing coronary artery bypass graft alone. Am Heart J, 1999; 138: 791-797.

25. Conradi L, Seiffert M, Franzen O et al. First experience with transcatheter aortic valve implantation and concomitant percutaneous coronary intervention. Clin Res Cardiol, 2011; 100: 311-316.

26. Serruys PW, Morice MC, Kappetein AP et al. Percutaneous coronary intervention versus coronary-artery bypass grafting for severe coronary artery disease. New Engl J Med, 2009; 360: 961-972.

27. Mack MJ, Banning AP, Serruys PW et al. Bypass versus drug-eluting stents at three years in SYNTAX patients with diabetes mellitus or metabolic syndrome. Ann Thorac Surg, 2011; 92: 2140-2146

28. Kodali SK, Williams MR, Smith CR et al. Two-year outcomes after transcatheter or surgical aortic-valve replacement. New Engl J Med, 2012; 366: 1686-1695.

29. Bonow RO, Carabello BA, Chatterjee K et al. 2008 Focused update incorporated into the ACC/AHA 2006 guidelines for the management of patients with valvular heart disease: A report of the American College of Cardiology/American Heart Association Task Force on Practice Guidelines (Writing Committee to Revise the 1998 Guidelines for the Management of Patients With Valvular Heart Disease): Endorsed by the Society of Cardiovascular Anesthesiologists, Society for Cardiovascular Angiography and Interventions, and Society of Thoracic Surgeons. Circulation, 2008; 118: e523-e661. 